\title{
Os Vinte e Quatro Anos do Sistema de Solução de Controvérsias do Mercosul e o Caso de Suspensão do Paraguai
}

\section{The Twenty Four Years of Mercosur's Dispute Settlement System and the Suspension of Paraguay}

\author{
Ricardo Soares Stersi dos Santos \\ Universidade Federal de Santa Catarina, Florianópolis - SC, Brasil \\ Rafael de Miranda Santos \\ Universidade Federal de Santa Catarina, Florianópolis - SC, Brasil
}

Resumo: Este artigo apresenta as transformações ocorridas no sistema de solução de controvérsias do Mercosul. Há indicações de que a resolução de controvérsias no Mercosul segue um modelo tradicional nas relações internacionais, combinando etapas em que os membros decidem como solucionar seus conflitos com etapas atribuídas a órgãos jurisdicionais: tribunais arbitrais "ad hoc" e/ou o Tribunal Permanente de Revisão. Apresenta, ainda, os aspectos gerais e relevantes do caso que gerou o afastamento do Paraguai dos órgãos deliberativos do Mercosul e analisa os aspectos processuais do litígio e o seu reflexo no sistema de solução de controvérsias.

Palavras-chave: Solução de Conflitos no Mercosul. Suspensão do Paraguai. Tutelas de Urgência.
Abstract: This article presents the transformations that occurred within Mercosur's dispute settlement system. It indicates that the settlement of disputes within Mercosur follows a traditional pattern in International Relations, combining steps in which the States themselves decide how to resolve their conflicts with proceduresin which decisions to put an end to the dispute are assigned to certain courts: "ad hoc" courts of arbitration and/or the Permanent Review Tribunal.It presents general and relevant aspects of the case which led to the suspension of Paraguay from the deliberative bodies of Mercosur, and also analyzes and interprets the procedural aspects of the case and its consequences to the Mercosur's dispute settlement system.

Keywords: Mercosur Dispute Settlement. Suspension of Paraguay. Interim Measures.

Recebido em: 31/07/2014

Revisado em: 15/04/2015

Aprovado em: 19/05/2015 


\section{Introdução: a construção do Mercosul}

Em novembro de 2015 completa-se 24 anos da entrada em vigor do Tratado de Assunção, marco de criação do Mercosul. Concomitantemente,há os 24 anos de instituição do sistema de solução de controvérsias do Mercosul, com a sua primeira configuração estabelecida no Anexo III do Tratado de Assunção.

A constituição do Mercosul pode ser enquadrada dentro do marco teórico Kantiano das Relações Internacionais.

Para Kant (2004), a possibilidade de criação de um ambiente de paz perpétua necessitava da sua regulação pelo Direito. No segundo dos artigos definitivos para se alcançar a paz perpétua, Kant pensava num Direito Internacional fundamentado numa Federação de Estados livres em que cada Estado estaria vinculado a comportamentos regrados pelo Direito Internacional de forma a não se constituir numa ameaça à liberdade dos demais. Kant apregoava que o crescimento da Federação de Estados livres se daria paulatinamente, com a razão atuando para criar a consciência necessária à transformação dos agentes. Para Kant a Federação de Estados livres deveria ser alcançada com o estabelecimento de Repúblicas e de Constituições republicanas nos Estados, já que esse modelo de Estado tende à paz perpétua. A Federação de Estados livres e o ambiente de paz perpétua não significariam, entretanto, ausência de conflitos. Eles seriam direcionados e solucionados pela aplicação do Direito por meio de métodos pacíficos e não pela guerra.

Bull (2002, p. 33) descreve que a tradição kantiana:

Assume que a natureza essencial da política internacional não reside no conflito entre estados, mas nos vínculos sociais transnacionais entre os seres humanos, que são súditos ou cidadãos de algum estado. Para os kantianos, o tema dominante das relações internacionais parece ser o relacionamento entre estados, mas é na realidade a relação entre todos os homens, participantes da comunidade representada pela humanidade, a qual existe potencialmente, embora não de modo efetivo, e que quando aflorar fará com que o sistema dos estados vá para o limbo. 
A história política do Cone Sul não é a de um ambiente de paz. Durante o século XIX foram relativamente numerosos os conflitos armados entre os países da região, principalmente entre Brasil e Argentina. Entre os quatro Estados fundadores do Mercosul (Argentina, Brasil, Paraguai e Uruguai) ocorreu a guerra de proporções mais calamitosa da América do Sul ${ }^{1}$.

Apesar de inúmeras tentativas de substituição do modelo de uso da violência por outros de viés cooperativo ${ }^{2}$, o século XIX é marcado pelo emprego da guerra na América do Sul, em conflitos de grande magnitude.

No final do século XIX e no século XX, as disputas entre os Estados da região sofrem uma mudança de cultura e passam a ser resolvidas primordialmente por meios pacíficos, influenciados pelas ideias das Conferências de Haia, da criação e participação dos Estados na Sociedade das Nações e, após a Segunda Guerra Mundial, pela criação da ONU e da OEA.

A criação do Mercosul em 1991, tendo como força motriz central o comércio, os sistemas democráticos de governo, a solução pacífica de conflitos e a regulação pelo Direito de Integração e pelo Direito Internacional, reproduziu o modelo Kantiano já experimentado anteriormente nas Américas $^{3}$ e na Europa ${ }^{4}$.

A partir das influências Kantianas, os processos de integração regionais se fundam em marcos jurídicos (Direito de Integração), já quese espera o cumprimento voluntário das condutas programadas e, em caso de conflitos, aaplicabilidade e a efetivação do Direito de Integração se darão por meio de instrumentos pacíficos de resolução de conflitos.

\footnotetext{
A guerra do Paraguai que teve o Paraguai de um lado e o Brasil, Argentina e Uruguai do outro iniciou-se em 1864 e findou em 1870, com a morte de Solano Lopez. Apesar das discordâncias sobre os números, reconhece-se uma diminuição substancial da população paraguaia após o final do conflito, sendo estimativas que vão de 30 a 70\% da população, além das perdas civis e militares entre os demais Estados. (DORATIOTO, 2002)

2 Para um histórico da cooperação estatal na América do Sul, no século XIX, cf. em Santos (1998, p. 23-36).

3 Em experiências anteriores como a Alalc, Aladi, Mercado Comum Centro-americano, Pacto Andino etc.

4 Em experiências como o Benelux e a União Europeia.
} 
Dessa forma, existência de um sistema de solução de controvérsias que possa ter atuação efetiva é assunto relevante num processo de integração. O incremento dos níveis de integração econômica e política, objetivos do processo de integração no Cone Sul, geraram uma profusão nas relações entre os seus Estados-Partes e a instituição de um centro diferenciado de tomada de decisões além dos governos dos Estados-Partes.

Tornou-se um senso relativamente comum na Academia, ainda que de difícil comprovação, afirmar que a existência de uma ordem jurídica própria e de um sistema de solução de controvérsias bem organizado, em que essa ordem jurídica possa ser interpretada e aplicada, tende a aprofundar a integração e gerar uma maior credibilidade no processo (provavelmente motivado pela importante atuação do Tribunal de Justiça da União Europeia que, por meio dos seus julgados, produziu importantes impactos no referido processo de integração).

Por outro lado também está presente a ideia de que o direito (incluindo-se o de integração) é uma estrutura poderosa no estabelecimento de ordem e de justiça nas relações entre os Estados.

Partindo das referidas premissas pretende-se, neste trabalho, apresentar as transformações do sistema de solução de controvérsias do Mercosul, desde a sua criação; destacar as suas características atuais e, por fim, expor o último caso levado à jurisdição do Tribunal Permanente de Revisão: referente à crise provocada pela modificação de governo no $\mathrm{Pa}$ raguai - impedimento do Presidente Lugo - e a suposta ruptura da ordem democrática no Paraguai, analisando os pontos centrais do caso.

\section{Objetivos do Mercosul}

São objetivos declarados no Tratado de Assunção: a ampliação das dimensões dos mercados dos Estados-Partes como condição fundamental para acelerar o desenvolvimento econômico com justiça social; o aproveitamento eficaz dos recursos disponíveis; a preservação do meio ambiente; o melhoramento das interconexões físicas; a coordenação de políticas macroeconômicas e a complementação dos diferentes setores da economia; a busca por uma adequada inserção internacional dos Estados-Partes; a 
necessidade de promover o desenvolvimento científico e tecnológico dos Estados-Partes e de modernizar suas economias para ampliar a oferta e a qualidade dos bens de serviço disponíveis, a fim de melhorar as condições de vida de seus habitantes; "[...] o estabelecimento das bases para uma união cada vez mais estreita entre os povos".(MERCOSUL, 2014e, grifos dos autores)

Trata-se de uma gama de interesses de natureza econômica, política, social e cultural que, uma vez alcançados, implicarão numa transformação dos setores atingidos.

Para a materialização de todos esses objetivos foi estabelecida uma série de instrumentos destinados à consecução dos interesses manifestos pelos Estados-Partes no Tratado, além de outros interesses próprios dos Estados-Partes que vão surgindo ao longo do tempo, bem como os interesses de grupos próprios que surgiram com a criação da organização internacional designada Mercosul.

A estrutura institucional do Mercosul, com os seus órgãos com poderes consultivos ou decisórios (incluindo-se o sistema de solução de controvérsias) e a ordem jurídica da integração são alguns dos instrumentos estabelecidos para a realização dessa multiplicidade de objetivos, buscados pelos diversos atores envolvidos no processo de integração.

Atualmente a estrutura institucional do Mercosul é constituída pelos seguintes órgãos com características intergovernamentais, dotados de poder decisório e com competência legal para estabelecer normas de direito da integração: Conselho Mercado Comum, Grupo Mercado Comum e Comissão de Comércio. A estrutura institucional também conta com as seguintes instituições com poderes consultivos: Parlamento do Mercosul (Parlasul) e Foro Econômico e Social. Por fim, o Mercosul ainda possuí uma Secretaria administrativa.

A estrutura institucional é completada pelo sistema de solução de controvérsias do Mercosul que é constituído por tribunais arbitrais " $a d$ hoc" e pelo Tribunal Permanente de Revisão, ambos com natureza jurisdicional. 


\section{Marcos Normativos e a Organização do Sistema de Solução de Controvérsias}

O primeiro marco normativo do sistema de solução de controvérsias foi estabelecido pelo Anexo III do Tratado de Assunção e previa:

a) Legitimidade para agir: possibilidade de utilização do sistema apenas pelos Estados-Partes.

b) Competência quanto à matéria: aplicação das normas estabelecidas pelo Tratado de Assunção.

c) Organização do sistema: pautava pela existência apenas de etapas autocompositivas. Iniciava pelas negociações diretas entre as partes envolvidas sem prazo fixado para o término. Caso não houvesse acordo entre as partes, estas deveriam solicitar a intervenção do Grupo Mercado Comum (GMC). Durante a conciliação perante o GMC, caso houvesse necessidade de esclarecimento de questões técnicas, o referido órgão poderia solicitar parecer a grupos de especialistas ou de peritos. Com ou sem assessoramento técnico, o GMC, dentro de um prazo de até 60 dias emitiria um parecer sobre o conflito, interpretando o Direito de Integração e recomendando comportamentos compatíveis com a ordem jurídica, caso entendesse ter ocorrido uma violação da mesma. A própria tomada de decisão para o estabelecimento de recomendações pelo GMC era (e continua sendo) complexa uma vez que o órgão só decide por meio de consenso. Dessa forma qualquer representante de Estado Parte poderia bloquear a decisão atinente ao estabelecimento de recomendações. De qualquer maneira as recomendações emitidas pelo GMC não eram obrigatórias ou vinculativas de forma que os Estados-Partes poderiam ou não acatar as recomendações. Caso não acatassem as recomendações sugeridas pelo GMC o assunto seria levado à apreciação do Conselho Mercado Comum (CMC) para que este, dentro das suas competências, adotasse as medidas necessárias para que as recomendações do GMC pudessem ser efetivadas. Assim como o $\mathrm{GMC}$, o CMC só toma decisões por meio de consenso. 
Sendo assim, qualquer representante de Estado Parte no CMC poderia impedir a adoção de qualquer medida necessária a implementação das recomendações do GMC.

d) Atualização do Sistema: O Tratado previa um prazo de 120 dias para que o GMC fizesse uma proposta de sistema provisório de solução de controvérsias, que vigoraria até a constituição do Mercado Comum prevista para 31 de dezembro de 1994. Após atingir a etapa de constituição de um Mercado Comum, seria apresentada uma proposta definitiva para o sistema de solução de controvérsias. Como até o presente momento o Mercosul não se constituiu como um Mercado Comum, o sistema de solução de controvérsias, apesar das suas transformações, continua sendo provisório.

O segundo marco normativo foi o Protocolo de Brasília, celebrado em

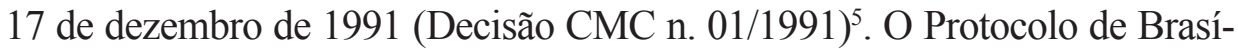
lia reconhecia a transitoriedade do sistema de solução de controvérsias. Inovou em relação ao Anexo III do Tratado de Assunção ao conjugar etapas autocompositivas com uma etapa heterocompositiva (arbitragem ad hoc).

A legitimidade de agir e a competência quanto à matéria continuaram as mesmas. O sistema somente admitia nos polos ativo e passivo dos procedimentos os Estados-Partes em litígios referentes à interpretação e aplicação do Direito de Integração (originário e derivado). A competência para a resolução dos conflitos oriundos das matérias estabelecidas em seu artigo primeiro era exclusiva e versava sobre a aplicação, interpretação ou o não cumprimento do Direito de Integração (originário e derivado).

As etapas iniciais, autocompositivas, começavam com as negociações diretas entre as partes, após comunicação oficial à Secretaria do Mercosul (SM). Caso as partes chegassem a um acordo sobre o litígio comunicariam a SM a decisão e o conteúdo do acordo. Em caso de descumprimento do acordo celebrado a parte prejudicada poderia dar sequência ao procedimento de solução de controvérsias solicitando a intervenção do

Vigente a partir de 16 de julho de 1993. 
GMC, independentemente do tempo transcorrido, já que a etapa de negociações diretas teria sido cumprida. ${ }^{6}$

Decorrido o prazo sem que as partes envolvidas chegassem a um acordo (15 dias prorrogáveis) ainda que parcial, o caso era remetido ao GMC para que (com ou sem auxilio de especialistas) emitisse ou não um parecer sobre a questão, num prazo de 30 dias. Os pareceres do GMC continuaram desprovidos de obrigatoriedade e a tomada de decisão permaneceu com a regra do consenso. ${ }^{7}$

Vencida as etapas autocompositivas sem que as partes tivessem solucionado a controvérsias, elas poderiam solicitar a instauração de tribunal arbitral $a d h o c^{8}$, por meio de comunicação a SM.

Na etapa heterocompositiva seria produzida uma decisão obrigatória e vinculativa para as partes. Os laudos arbitrais proferidos pelos tribunais arbitrais ad hoc eram inapeláveis, fazendo coisa julgada. Admitiase, entretanto, o pedido de esclarecimento do julgado ou de interpretação quanto às maneiras de cumpri-los.

Caso não ocorresse o cumprimento voluntário da decisão proferida, no prazo fixado no laudo arbitral, o Estado Parte reclamante poderia adotar medidas compensatórias (coercitivas) em relação ao Estado infrator.

As medidas compensatórias previstas pelo Protocolo de Brasília se diferenciavam das ações típicas de autotutela. Na autotutela os atos de for-

6 Tal interpretação se baseia no conteúdo do laudo arbitral IX. No referido laudo, uma das alegações da Argentina era o descumprimento de acordo celebrado no âmbito de negociações diretas com o Uruguai.

7 No sistema de solução de controvérsias do Mercosul o GMC, atuando como conciliador, não conseguiu consenso para emitir nenhum parecer sobre um caso. Nos laudos arbitrais III, IV e VIII, emitidos durante a vigência do Protocolo de Brasília, há referência expressa no próprio laudo que o GMC não conseguiu chegar a qualquer decisão, deixando de oferecer recomendações às partes.

8 A expressão ad hoc, comum na arbitragem, diz respeito aos tribunais arbitrais constituídos para cada ocasião. A arbitragem ad hoc se contrapõe a arbitragem institucional onde as regras estão previamente determinadas nos regulamentos de arbitragem, os árbitros são escolhidos a partir de listas reconhecidas pelo órgão administrador da arbitragem. O Tribunal Permanente de Revisão quando atua como órgão arbitral o faz de forma institucional e não ad hoc. 
ça física, moral, econômica, etc., são utilizados para que o adversário se submeta a noção de justiça imposta pelo outro, alterando o comportamento que a viole. Não há apreciação sobre a existência ou não do suposto direito violado por um órgão jurisdicional independente, neutro e imparcial. $\mathrm{Na}$ autotutela, a interpretação e a aplicação do direito ocorrem de maneira unilateral. A sua efetivação é realizada por meio de atos de violência.

No âmbito do Protocolo de Brasília, as medidas compensatórias (ações coercitivas) apenas poderiam ser adotadas (como instrumento de sanção e não como forma de resolução dos conflitos) após decorrido o prazo fixado no pronunciamento do órgão jurisdicional (tribunal arbitral ad hoc), onde houvesse sido reconhecida uma situação de violação do Direito de Integração e caso não houvesse o cumprimento voluntário integral da decisão proferida pelo órgão jurisdicional.

Criou-se também, via $\mathrm{PB}$, um mecanismo meramente subsidiário para as reclamações de particulares que deveriam ser filtradas e eventualmente encampadas pelas seções nacionais do GMC. ${ }^{9}$ Entretanto as decisões adotadas no sistema só poderiam ser exigidas por um Estado Parte em relação a outro Estado Parte. Em virtude da restrição, quanto à legitimidade para atuar no sistema, um particular jamais poderia ser beneficiado diretamente por uma decisão proveniente do sistema (restrição que perdura até os dias atuais) ${ }^{10}$.

Nos procedimentos instaurados a partir das reclamações de particulares encampadas pela Seção Nacional do Estado Parte, a etapa de negociações diretas entre os Estados-Partes em conflito tornava-se facultati-

9 Durante a vigência do Protocolo de Brasília houve um caso iniciado a partir da reclamação de um particular. A reclamação foi apresentada pela Cia Industrial de Tabacos Monte Paz S/A a Seção Nacional uruguaia do GMC. As negociações diretas com o Brasil não prosperaram e a questão foi submetida ao GMC que designou grupo de especialistas para opinar sobre a procedência ou não da reclamação. O grupo de especialistas apresentou, ao GMC, parecer favorável a procedência da reclamação. Nos termos do artigo 32 do PB, o Uruguai requereu medidas corretivas e/ou anulatórias a serem realizadas pelo Brasil que deixou de realizá-las no prazo estipulado. A partir disso a questão foi submetida a arbitragem ad hoc.

10 Nesse sentido, cf. em Magalhães (2003, p. 71-72). 
va, já que o Estado reclamante poderia levar a controvérsia diretamente a apreciação do GMC.

O PB sofreu algumas modificações introduzidas pelo Protocolo de Ouro Preto (POP), celebrado em 17 de dezembro de 1994.

A principal modificação que foi trazida pelo Protocolo de Ouro Preto foi a criação da Comissão de Comércio do Mercosul (CCM). A esse novo órgão foi atribuída diversas competências, entre elas a de atuar na solução de controvérsias envolvendo matérias comerciais. A referida competência não era exclusiva de forma que a questão poderia ser submetida ao mecanismo padrão de solução de controvérsias estabelecida pelo Protocolo de Brasília.

Tal como no mecanismo padrão, a competência é exclusiva dos Estados-Partes para figurar no pólo ativo e passivo das demandas. Os particulares poderiam apresentar reclamações pela via das seções nacionais da CCM. Somente nas situações de encampação da reclamação do particular pelo Estado Parte é que a matéria poderia ser submetida à variável do sistema de solução de controvérsias criado pelo POP.

A novidade dessa variável do sistema era somente a possibilidade de intervenção (conciliação) da CCM, que poderia emitir recomendações sobre o conflito. Funcionaria com uma etapa autocompositiva (conciliação perante a CCM e, em certos casos, perante o GMC) e, na falta de cumprimento das recomendações emitidas ou na ausência de recomendações (em virtude de falta de consenso), a possibilidade de instauração da etapa heterocompositiva (arbitragem ad hoc). ${ }^{11}$

O POP também modificou a previsão para a adoção de um sistema permanente de solução de controvérsias. Anteriormente o sistema permanente seria adotado com a instituição do Mercado Comum. No POP a previsão para a adoção de um sistema permanente de solução de controvérsias foi antecipado para antes do final da etapa de União Aduaneira.

\footnotetext{
11 Dois casos submetidos à arbitragem ad hoc, durante a vigência do $\mathrm{PB}$, utilizaram a variável de solução de controvérsias da CCM (laudos I e II). Em nenhum dos casos houve consenso na CCM para a emissão de recomendações.
} 
Durante a vigência do Protocolo de Brasília e das alterações trazidas pelo Protocolo de Ouro Preto, dez laudos arbitrais foram proferidos pelos tribunais arbitrais ad hoc.

O quarto e último marco normativo, atualmente vigente, foram estabelecidos pelo Protocolo de Olivos (PO), celebrado em 18 de fevereiro de 2002.

O PO trouxe alterações substanciais em relação ao PB.

A primeira delas é a transformação do foro obrigatório e exclusivo do sistema de solução de controvérsias do Mercosul em competência facultativa. Dessa forma, qualquer Estado Parte poderá optar porsubmeter seus litígios a outro sistema de solução de controvérsias ${ }^{12}$ quando houver concorrência em relação à matéria objeto do conflito - uma parte substancial das normas da integração concorre com as normas de liberalização do comércio internacional, sob a égide da Organização Mundial do Comércio $(\mathrm{OMC})$.

No PO criou-se outro órgão jurisdicional para a solução de conflitos: o Tribunal Permanente de Revisão (TPR).

O TPR possui um rol significativo de competências estabelecidas pelo PO, combinando as decisões obrigatórias e vinculativas, de natureza jurisdicional, com certas competências meramente consultivas (decisões não obrigatórias e não vinculativas). A previsão para a criação de mecanismos de atuação consultiva do TPR foi estabelecida pelo artigo $3^{\circ}$ do PO. As matérias suscetíveis de utilização da atuação consultiva do TRP foram criadas pela Decisão CMC n. 37/2003.

Entre as competências consultivas criadas pela Decisão CMC n. 37/2003, encontram-se:

a) a competência para emitir parecer sobre qualquer questão jurídica atinente ao direito de integração, inclusive no que tange a legitimidade e a legalidade das decisões provenientes dos órgãos do Mercosul que detém poderes decisórios e vinculativos (CMC,

12 A referida mudança permite a opção principalmente de utilização do Sistema de Solução de Controvérsias da Organização Mundial do Comércio. 
GMC e CCM). O rol de atores legitimados para utilizar a referida competência é: 1) Os Estados-Partes do Mercosul, atuando em conjunto (mediante consenso) ${ }^{13}$, bem como dos órgãos do Mercosul que possuem poderes decisórios e vinculativos (CMC, GMC, CCM) ${ }^{14}$.

b) a competência para emitir parecer sobre a interpretação adequada do direito de integração em casos concretos submetidos aos Poderes Judiciários dos Estados-Partes e desde que solicitado pelos Tribunais Superiores do Estado Parte que retiver a jurisdição sobre o caso. A matéria foi regulamentada pela Decisão CMC n. 02/2007 e até o presente momento foram formuladas duas consultas. O mecanismo tem claramente como fonte de inspiração o procedimento de reenvio prejudicial, estabelecido na União Europeia.

c) Nas etapas da resolução de conflitos em virtude do descumprimento do direito de integração pelos Estados-Partes, mantevese a estrutura estabelecida pelo $\mathrm{PB}$, com as modificações introduzidas pelo POP: i) a etapa de negociação direta mediante a

13 Conforme a CMC n. 37/2003, os Estados-Partes devem acordar quanto ao objeto e o conteúdo do projeto de consulta ao TPR. Estabelecido o consenso sobre o projeto de consulta, o documento é encaminhado a Presidência Pro-Tempore que ficará encarregada de redigir, a partir do projeto de consulta, o texto da consulta que será apresentado ao TPR. A consulta deve ser encaminhada por escrito a Secretaria do TPR indicando de forma clara as questões atinentes, a sua motivação, as normas do direito de integração vinculadas ao objeto e todos os documentos que possam ser úteis na manifestação do TPR. O TPR apresentará parecer (resposta) as consultas em um prazo de até 45 dias contados da data do protocolo da consulta na Secretaria do TPR.

14 Conforme a CMC n. 37/2003, o CMC, o GMC e a CCM poderão solicitar consultas desde a intenção de formula-las, bem como o seu conteúdo e objeto constem de ata de reunião do órgão. A solicitação da consulta é encaminhada a Presidência Pro-Tempore do Mercosul que ficará encarregada de redigir, a partir da ata da reunião do órgão que a solicitou, o texto da consulta que será apresentado ao TPR. A consulta deve ser encaminhada por escrito a Secretaria do TPR indicando de forma clara as questões atinentes, a sua motivação, as normas do direito de integração vinculadas ao objeto e todos os documentos que possam ser úteis na manifestação do TPR. O TPR apresentará parecer (resposta) as consultas em um prazo de até 45 dias contados da data do protocolo da consulta na Secretaria do TPR. 
comunicação a SM continuou obrigatória; ii) a etapa de conciliação perante o GMC continuou facultativa; iii) a possibilidade de reclamação de particulares às Seções Nacionais do GMC não sofreu qualquer alteração; iv) as reclamações perante a CCM continuaram vinculadas às mesmas matérias e com o mesmo procedimento.

A modificação substancial ocorreu no que concerne à etapa heterocompositiva do procedimento por descumprimento.

Os Estados-Partes envolvidos no litígio poderão eleger: a) uma etapa jurisdicional com duplo grau de jurisdição, sendo o primeiro grau produzido por decisão proferida pelo tribunal arbitral ad hoc e o segundo grau de jurisdição, por meio de recurso julgado pelo TPR; b) uma etapa com um único grau de jurisdição (sem a possibilidade de recurso quanto ao mérito da decisão) cuja competência para proferir a decisão será do TPR.

Além das modificações, no que concerne à escolha de duplo grau de jurisdição ou de um único grau de jurisdição, o PO também inovou ao instituir um controle jurisdicional sobre o cumprimento efetivo ou não dos laudos proferidos e sobre o limite das medidas coercitivas aplicadas nas hipóteses de falta de cumprimento integral dos laudos.

As medidas coercitivas autorizadas, nas situações de descumprimento dos laudos proferidos, continuaram sendo realizadas por meio de medidas compensatórias. Nos termos do artigo xx do PO, as medidas compensatórias devem ser adotadas na mesma área da infração cometida. Se não foremsuficientes ou inadequadas, essas medidas poderão ser aplicadas em área diversa da infração cometida.

Para Santos (2010), o TPR é um órgão jurisdicional com natureza híbrida, ao agregar algumas características que são próprias de instituições judiciais internacionais, aproximando-o da estrutura permanente de órgãos como a Corte Internacional de Justiça e o Tribunal de Justiça da Comunidade Andina de Nações. O TPR pode ser analisado como um órgão de transição entre uma corte arbitral e uma corte judicial, já que não há, como nos tribunais arbitrais "ad hoc", uma maior liberdade na escolha dos julgadores que decidirão os litígios. 


\section{O Impedimento do Presidente Lugo e a Alegação da Ruptura da Ordem Democrática no Paraguai}

No ano de 2012 ocorreu o ápice da crise institucional entre o Presidente Lugo e o Congresso paraguaio. Sem dispor de apoio político dos partidos tradicionais o Presidente Lugo enfrentava uma esmagadora maioria contrária ao seu governo no Congresso paraguaio.

$\mathrm{O}$ advento do enfrentamento armado entre forças policiais e militares paraguaias e grupos de sem terra (conhecidos como "carperos") na localidade de Curuguaty, com 17 mortes (11 carperos e 6 policiais), ocorrido em 15 de junho de 2012, foi o estopim para o início do processo de impedimento do Presidente paraguaio.

Em processo sumário, o Presidente Lugo foi acusado na Câmara dos Deputados, no dia 21 de junho de 2012, por cinco crimes: uso indevido de quartéis militares, confronto em Curuguaty, invasão de terras na região de Ñacunday, insegurança no Paraguai e a assinatura do Protocolo de Ushuaia II (que deve substituir o primeiro Protocolo de Ushuaia). A Câmara dos Deputados aprovou em poucas horas o início do processo de impedimento por 76 votos a favor e um contra. No dia posterior (22 de junho de 2012), o processo de impedimento foi julgado pelo Senado paraguaio que aprovou a destituição do Presidente Lugo com 39 votos (eram necessários 30 votos favoráveis), quatro votos contrários e dois abstenções. Todo o processo de impedimento ocorreu em pouco mais de 24 horas (denúncia na Câmara dos Deputados até a votação do impedimento pelo Senado paraguaio). Reconhecendo a inexistência do devido processo legal (e a possibilidade de ampla defesa) no processo de impedimento, bem como o mascaramento de um golpe de estado, as principais organizações internacionais latino-americanas condenaram a decisão de destituição do Presidente paraguaio.

Após o seu afastamento da presidência, o PresidenteLugo ajuizou ação pretendendo à anulação do procedimento sumário, perante o Congresso paraguaio, que levou a sua destituição do cargo. Alegava a violação do devido processo legal já que o seu prazo de defesa foi de apenas 24 horas. A Corte Suprema de Justiça do Paraguai deixou de acolher a 
pretensão de Lugo. No julgado reconheceu que o processo de destituição é um juízo político e que como tal não se aplicariam as regras do devido processo legal, que cabem nos juízos ordinários. Acabou apenas recomendando que o Congresso paraguaio regulamentasse as regras atinentes ao tempo de defesa dos juízos políticos.

\section{A Suspensão do Paraguai dos Órgãos com Poderes Decisórios do Mercosul e o Laudo n. 1/2012 do TPR}

Após a destituição do Presidente Lugo das funções presidenciais, o Mercosul se manifestou por meio de decisão dos Chefes de Estados, em 29 de junho de 2012, durante a $18^{\text {a }}$ Reunião do Conselho Mercado Comum, ocorrida na cidade de Mendoza. Na decisão dos Chefes de Estados dos demais países membros do Mercosul ficou determinada a suspensão da participação do Paraguai nos órgão deliberativos do Mercosul, até o retorno da ordem democrática naquele país ${ }^{15}$.

O amparo legal para a suspensão da participação paraguaia no Mercosul foi o Protocolo de Ushuaia, celebrado em 24 de julho de 1998 e ratificado por todos os Estados-Partes do Mercosul, além do Chile e da Bolívia (Estados Associados) ${ }^{16}$.

O Protocolo de Ushuaia estabelece em seu artigo 1, o compromisso dos Estados Partes em manter a plena vigência de instituições democráticas como uma condição primordial para o desenvolvimento da integração regional.

${ }^{15}$ Conforme o item 5 do Comunicado Conjunto dos Presidentes dos Estados-Partes do Mercosul: Reiteraron su condena a la ruptura delorden democrático producida en la hermana República del Paraguay, subrayaron que el restablecimiento de las instituciones democráticas es condición indispensable para el desarrollo del proceso de integración y decidieron suspender, enel marco del Protocolo de Ushuaia sobre Compromiso Democrático del MERCOSUR, elderecho de ese país a participar en losórganos del MERCOSUR. Resaltaron su compromiso con que los efectos de la aplicación de esta medida no causen perjuicios al pueblo paraguayo. La suspensión cesará cuando, de acuerdo a lo establecido en el artículo $7^{\circ}$ del Protocolo de Ushuaia, se verifique el pleno restablecimiento del orden democrático en la parte afectada.

${ }^{16}$ Conforme o artigo 5 do Protocolo de Ushuaia. 
O referido Protocolo apesar de não definir claramente o que seja a ruptura da ordem democrática, estabelece o procedimento necessário para que o Estado infrator possa vir a ser sancionado caso se entenda ter ocorrido a aludida ruptura: a) consulta entre os Estados-Partes, incluindo o Estado afetado, buscando investigar a situação e verificar a possibilidade de equacionamento do problema por meio de um acordo entre todos que garanta a plena vigência de instituições democráticas no Estado afetado; b) em caso de fracasso da consulta realizada com o Estado afetado, os demais Estados, levando em conta a gravidade da violação do compromisso democrático e a natureza e o alcance das sanções previstas no Protocolo, decidirão pela aplicação ou não das sanções previstas no artigo 5: suspensão do direito de participar dos diferentes órgãos dos processos de integração; suspensão dos direitos e obrigações decorrentes dos processos de integração.

A partir da decisão de suspensão do Paraguai dos órgãos do Mercosul, a mesma reunião do Conselho Mercado Comum tomou a decisão de considerar incorporada a Venezuela como novo Estado Parte do Mercosul, a partir de 31 de julho de $2012^{17}$.

O Protocolo de adesão da Venezuela ao Mercosul havia sido celebrado com Estados-Partes do Mercosul em 4 de julho de 2006, estabelecendo uma série de obrigações a serem cumpridas pela Venezuela e demandando a ratificação por todos os Estados envolvidos. A adesão da Venezuela só ocorreria 30 dias após o último depósito de ratificação do Protocolo. O único Estado que ainda até então não havia ratificado o Protocolo era justamente o Paraguai. A decisão do Conselho Mercado Comum que, na prática, considerou cumpridas as exigências legais para o ingresso da Venezuela ignorava os dispositivos do próprio Protocolo de adesão, entre eles o que exigia a ratificação por todos os Estados-Partes.

17 Conforme o item 6 do Comunicado Conjunto dos Presidentes dos Estados-Partes do Mercosul: Se congratularon por el ingreso de la República Bolivariana de Venezuela al MERCOSUR, subrayando que elproceso de integración es un instrumento para promover el desarrollo integral, enfrentar la pobreza y la exclusión social. Convocaron, para ello, a una reunión a los fines de la admisión oficial de Venezuela al MERCOSUR el 31 de julio de 2012, en la ciudad de Río de Janeiro. 
Poucos dias depois da reunião do Conselho Mercado Comum que suspendeu o Paraguai dos órgãos deliberativos do Mercosul e declarou o ingresso da Venezuela, o Senado paraguaio votou pela não ratificação do Protocolo de adesão da Venezuela ao Mercosul.

Inconformado com a decisão tomada pelos demais Chefes de Estado do Mercosul, o governo recém-empossado no Paraguai ingressou, em 9 de julho de 2012, com pedido de medidas de urgência, fundamentado no Procedimento para casos excepcionais de urgência estabelecido no artigo 24 do PO e regulamentado pela Decisão CMC n. 23/04.

$\mathrm{O}$ pedido paraguaio, fundamentado nos artigos 1 e 23 do PO e no artigo 2, b, da Decisão CMC 23/04, solicitava que o TPR: a) declarasse inaplicável a decisão da Reunião de Chefes de Estado do Mercosul que suspendeu o Paraguai dos órgãos decisórios do Mercosul uma vez que o procedimento previsto pelo Protocolo de Ushuaia não havia sido cumprido (especialmente as consultas prévias previstas no art. 4) e a Reunião de Chefes de Estado não é um órgão decisório da estrutura institucional pois não se constitui em qualquer das fontes do direito de integração estabelecidas pelo art. 41 do POP; b) declarasse inaplicável a decisão da Reunião de Chefes de Estado do Mercosul que reconheceu a incorporação da Venezuela como membro pleno do Mercosul, a partir de 31 de julho de 2012, visto que o Protocolo de adesão da Venezuela ao Mercosul não havia sido ratificado pelo Senado paraguaio, que havia sido desrespeitado os direitos e deveres do Paraguai como depositário do Protocolo de adesão, que não havia unaminidade na decisão de incorporação, conforme exige o artigo 20 do TA, e, por fim, que não havia sido respeitada a regra de vigência simultânea das normas estabelecidas pelos órgãos do Mercosul.

O Paraguai sustenta que não houve qualquer violação do PU porque a substituição de governo no Paraguai ocorreu nos termos da Constituição do país, tendo o antigo Presidente Lugo aceitado a decisão do Congresso paraguaio.

A justificativa do Paraguai de ingressar com a pretensão diretamente ao TPR ocorreu a partir de interpretação própria do TA, do POP, do PO e, principalmente, da Decisão CMC 23/04. Aponta que as demais instâncias previstas no PO estariam excluídas ao Paraguai diante da impossibi- 
lidade de participação dos representantes paraguaios, como consequência da suspensão ilegalmente imposta pelos demais Estados-Partes. Considera, assim, que o TPR teria competência originária para conhecer da controvérsia.

Os demais Estados-Partes do Mercosul (Argentina, Brasil e Uruguai) apresentaram defesa alegando: a) incompetência do TPR em razão da matéria, já que entendem que o sistema de resolução de conflitos do Mercosul se restringe a questões de natureza comercial e não as questões políticas contempladas pelo $\mathrm{PU}$; b) que o procedimento escolhido pelo Paraguai, estabelecido no artigo 24 do PO e regulamentado pela Decisão CMC n. 23/04, é inadequado para a questão já que o referido procedimento de medidas de urgência se restringe aos conflitos de natureza comercial; c) que a questão de mérito não pode ser analisada já que as etapas prévias estabelecidas no sistema de solução de controvérsias do Mercosulnão foram cumpridas (etapas autocompositivas) e os Reclamados não concordaram com a competência originária do TPR (etapa jurisdicional); d) no mérito argumentaram sobre a adequação e legitimidade das decisões questionadas pelo Paraguai quer no que diz respeito a suspensão ou no que diz respeito a incorporação da Venezuela. A legalidade da decisão de suspensão do Paraguai pela Reunião de Chefes de Estados se daria porque o artigo 5, do PU, não prevê qualquer rito solene ou formalidade para aplicar a suspensão, visto tratar-se de medida de natureza política e não jurídica. Eles entendem que a etapa prévia de consultas prévias, prevista pelo PU, foi cumprida, a despeito da alegação do Paraguai, uma vez que os representantes dos Estados-Partes teriam realizado diversas reuniões com vários atores políticos paraguaios buscando que fosse respeitado o direito de defesa e o devido processo legal no procedimento de impedimento do Presidente Lugo. Destaca-se, ainda, que a medida de suspensão do Paraguai nos termos em que foi tomada era a medida menos gravosa possível e tinha um caráter provisório.

Quanto à incorporação da Venezuela, a defesa utiliza uma diferenciação entre os atos de aprovação da solicitação de adesão e a declaração de incorporação do novo membro pleno. A primeira, nos termos do artigo 20 do TA, exigiria a unanimidade. A segunda, de natureza declaratória, não exigiria a unanimidade. Interpreta que o Protocolo de adesão da Ve- 
nezuela entraria em vigor, assim, 30 dias após a ratificação pelo último Estado Parte pleno de seus poderes (não suspenso). Caso fosse exigida a participação do Paraguai (Estado suspenso) das referidas decisões tal fato por si só tornariam inócuos os dispositivos do PU.

A decisão proferida pelo TPR enfrentou quatro grandes questões:

a) O TPR decidiu "exofficio" que ainda que o Paraguai tenha sido suspenso dos órgãos decisórios do Mercosul, na reunião de Chefes de Estado, a referida suspensão não atingia o seu direito de recorrer ao sistema de solução de controvérsias para contestar a legalidade da decisão.

b) Em relação à questão de incompetência ratione materiae do TPR o Tribunal reconheceu a sua competência em razão da matéria já que, nos termos do PO, o TPR têm competência para julgar os conflitos decorrentes da interpretação, aplicação e cumprimento do Direito de Integração originário e derivado. A questão do compromisso democrático previsto no TA e no PU compõe o Direito de Integração estabelecendo, assim, a competência em razão da matéria ao TPR para interpretar, aplicar e promover o cumprimento da referida norma.

c) Quantoà existência dos requisitos necessários para a concessão das medidas excepcionais de urgência solicitadas pelo Paraguai, o TPR acolheu a manifestação dos demandados reconhecendo que o pedido do Paraguai não cumpre os elementos exigidos no artigo $2^{\circ}$ da Decisão CMC n. 23/04. ${ }^{18} \mathrm{O}$ TPR entendeu que os requisitos indicados nas letras " $a$ " a " $d$ ”, do artigo $2^{\circ}$, precisam

18 Art. 2 Qualquer Estado Parte poderá recorrer ao Tribunal Permanente de Revisão (TPR) sob o procedimento estabelecido na presente Decisão sempre que se cumpram os seguintes requisitos:

${ }^{\mathrm{q}} \mathrm{ue}$ se trate de bens perecíveis, sazonais, ou que por sua natureza e características próprias perderam suas propriedades, utilidade e/ou valor comercial em um breve período de tempo, se foram retidos injustificadamente no território do país reclamado; ou de bens que estivessem destinados a atender demandas originadas em situações de crise no Estado Parte importador; que a situação se origine em ações ou medidas adotadas por um Estado Parte, em violação ou descumprimento de normativa MERCOSUL vigente; que a manutenção dessas ações ou medidas possam produzir danos graves e irreparáveis; que 
ser demonstrados de maneira cumulativa (e não independentes com fez o Paraguai), devendo, em consequência, estarem presentes todos os itens, e não apenas alguns deles (interpretação fundamentada no art. $6^{\circ}$ da Decisão CMC n. 02/04). Como a pretensão do Paraguai se fundamentava apenas nos itens " $b$ ” e " $c$ ” do artigo $2^{\circ}$, o TPR decidiu que não estavam presentes os requisitos para a utilização da Decisão CMC n. 23/04 ao caso apesar de reconhecer que três dos itens embasavam a pretensão do Paraguai (faltava o item “ $a$ ”).

d) O TPR reconheceu a impossibilidade de promover a apreciação da pretensão de mérito paraguaia em virtude de não estarem preenchidos todos os elementos de acesso direto ao TPR. Conforme o TPR, para a utilização do procedimento de acesso direto tanto o demandante quantos os demandados devem previamente expressar o seu consentimento a via única, fato não ocorrido já que Brasil, Uruguai e Argentina (demandados) não manifestaram o consentimento para a jurisdição direta do TPR. Também o Paraguai não respeitou o procedimento de acesso direto que exige uma etapa prévia de negociação direta entre as partes, mediante comunicação do denunciante a Secretaria do Mercosul.

\section{Análise e Conclusões sobre o Caso de Suspensão do Paraguai dos Órgãos Deliberativos do Mercosul}

A decisão do TPR produziu alguns direcionamentos (que poderão ser utilizados como jurisprudência para questões futuras).

A primeira dos direcionamentos se reflete no alcance das sanções previstas no PU. A suspensão de um Estado Parte dos órgãos deliberativos do Mercosul não alcança a possibilidade deste mesmo Estado continuar utilizando o sistema de solução de controvérsias, ainda que a representação do Estado nos casos passe a ser designada por governo surgido em razão de ruptura da ordem democrática (governo de fato). A suspensão do

as ações ou medidas questionadas não sejam objeto de uma controvérsia em curso entre as partes envolvidas. 
Estado não implica, também, no afastamento dos árbitros indicados pelo Estado infrator e que compõem as listas de julgadores do sistema de solução de controvérsias (tribunais arbitrais "ad hoc" e do TPR).

O segundo direcionamento diz respeito ao exercício de jurisdição do TPR. O TPR, analisando a sua competência jurisdicional, entendeu que as normas do PU compõem o Direito de Integração, cabendo aos órgãos jurisdicionais do sistema de solução de controvérsias analisar e decidir questões decorrentes da interpretação e aplicação do PU. Tal direcionamento implica na jurisdição para decidir não só em relação ao cumprimento formal das etapas do PU, mas, também, para analisar e decidir: a) se houve ou não ruptura da ordem democrática no Estado; b) se a sanção aplicada é proporcional a violação cometida pelo Estado do PU; c) em que momento ocorre a restauração da ordem democrática no Estado e, consequentemente, devem cessar as sanções aplicadas em decorrência do PU.

O terceiro direcionamento diz respeito ao alcance da Decisão CMC n. 23/04 e da competência originária do TPR para a concessão de medidas excepcionais de urgência. Segundo a decisão do TPR, a aplicação do artigo $2^{\circ}$ da Decisão CMC n. 23/04 só é possível na hipótese de cumprimento cumulativo da totalidade dos itens indicados na norma. A decisão do TPR também faz referência no sentido em que, presentes os requisitos do artigo $2^{\circ}$, o TPR reconhece que possui competência originária para a matéria (neste caso uma competência originária que independe de consenso prévio entre as partes).

O quarto direcionamento é no sentido de reconhecimento da limitação das hipóteses de jurisdição originária do TPR, que só ocorrem nos termos do artigo 23 e 24 do PO. Nos termos do artigo 23 só é possível à jurisdição originária mediante anuência expressa das partes. Nos termos do artigo 24 só é possível à jurisdição originária nos hipóteses de aplicação da Decisão CMC n. 23/04, explicada anteriormente.

Entretanto a decisão do TPR também fez surgir uma série de dúvidas sobre como teria sido a análise de mérito da questão. 
A primeira dúvida diz respeito ao órgão competente do Mercosul para analisar a questão referente a alegação de ruptura da ordem democrática nos Estados-Partes.

Teria a reunião de Chefes de Estado competência para deliberar sobre a matéria? A resposta é negativa já que a reunião de Chefes de Estado não está prevista, no Direito de Integração, como órgão deliberativo do Mercosul. Na prática as decisões tomadas nas reuniões de Chefes de Estado ingressam, posteriormente, no Direito de Integração, por meio das decisões vinculantes tomadas nos órgãos deliberativos do Mercosul (principalmente via CMC). Logo caberia ao CMC, por força do artigo 10 do $\mathrm{TA}^{19}$, tomar as decisões referentes à aplicação do PU, conforme a análise de Paz (2013) e de Lafer (2013).

A segunda dúvida diz respeito a se os demais Estados do Mercosul cumpriram o requisito previstos no PU, para deliberar sobre a ruptura de ordem democrática no Paraguai? Também nessa hipótese a resposta seria negativa, conforme Paz (2013) e Lafer (2013) já que não houve consultas prévias entre os demais Estados e o Paraguai para a adoção da medida de suspensão. Entende-se que as consultas prévias previstas no PU devem, por analogia, ter mecanismos formais, como aqueles que são exigidos para as negociações diretas entre os Estados-Partes no sistema de solução de controvérsias, ou seja, mediante comunicação a SM. Assim, os demais Estados-Partes do Mercosul tomaram a decisão de suspender o Paraguai dos órgãos deliberativos do Mercosul sem formalmente realizarem as consultas prévias.

A terceira dúvida é em relação ao critério para se considerar ocorrida à ruptura da ordem democrática num Estado Parte do Mercosul. No caso do Paraguai ocorreu a ruptura da ordem democrática no país? A resposta para essa questão já é mais difícil. A resposta afirmativa, como aquela manifestada por Garcia (2013), utiliza o raciocínio no sentido em que a substituição do governo eleito se deu por um arremedo de processo legal de "impeachment", já que o Presidente Lugo não dispôs de tem-

19 Art. 10 O Conselho é o órgão superior do Mercado Comum, correspondendo-lhe a condução política do mesmo e a tomada de decisões para assegurar o cumprimento dos objetivos e prazos estabelecidospara a constituição definitiva do Mercado Comum. 
po e meios efetivos para se defender, contrariando o princípio do devido processo legal (apontado como um princípio do Direito Internacional). Já a resposta negativa, sustentada por Paz (2013), considera as peculiaridades da Constituição do Paraguai (estabelecida por uma Assembleia Constituinte) e, ao mesmo tempo, o fato de que os requisitos constitucionais para a decretação do "impeachment" foram legalmente cumpridos, sendo, inclusive, a decisão do Congresso paraguaio, reconhecida como legal por decisão do órgão máximo do Poder Judiciário do Paraguai (Corte Suprema de Justiça). A Organização dos Estados Americanos (OEA), ao deliberar sobre o assunto, tomou a decisão de não suspender o Paraguai da organização por violação da cláusula democrática enquanto a decisão do Mercosul foi em sentido contrário. Para Lafer (2013), a decisão do Mercosul viola o princípio de direito internacional da não intervenção uma vez que a decisão não tem lastro em critérios jurídicos para a análise de rompimento da ordem democrática no Paraguai.

O caso de suspensão do Paraguai do Mercosul foi o último a utilizar o sistema de solução de controvérsias do Mercosul e a jurisdição do TPR. Foi o primeiro a invocar a aplicação da Decisão CMC n. 23/04, referente à aplicação das medidas excepcionais e de urgência, previstas no artigo 24 do PO, assim como reconhecer a jurisdição do TPR para interpretar e aplicar as normas do PU.

Apesar da sua pouca utilização, o sistema de solução de controvérsias, nesses 24 anos de atuação, tem tido um papel importante em produzir as respostas relativas à interpretação e à aplicação do Direito de Integração, bem como em promover a solução pacífica dos conflitos decorrentes do processo de integração.

O caso do Paraguai, que não teve o seu mérito apreciado por força de questões procedimentais, serviu, entretanto, para elucidar aspectos que anteriormente o TPR ainda não havia se pronunciado. A questão acabou sendo totalmente encerrada após a eleição do novo governo do Paraguai, ocorrida no ano de 2013.

Alguns aspectos legais, entretanto, acabaram momentaneamente sendo superados pelas ações políticas (como ocorre de maneira comum nas relações internacionais). Em dezembro de 2013, preparando o seu re- 
torno ao Mercosul, o novo governo eleito do Paraguai obteve, junto ao Senado paraguaio, uma mudança de posição do órgão legislador, o que permitiu a ratificação do Protocolo de adesão da Venezuela ao Mercosul, superando a discussão sobre a ilegalidade do ato de incorporação daquele país ao Mercosul realizada no ano de 2012.

Recentemente os representantes paraguaios retomaram as suas prerrogativas integrais perante os órgãos deliberativos do Mercosul.

É certo que o conflito relativo ao afastamento temporário do $\mathrm{Pa}$ raguai dos órgãos decisórios do Mercosul apontou alguns entraves processuais que devem ser objeto de aperfeiçoamento no sistema de solução de controvérsias do Mercosul. É preciso, também, fortalecer os aspectos jurídicos do sistema para que as decisões principais não venham a dar destaque apenas aos planos políticos ou econômicos do processo de integração, ainda que se reconheça o destaque e a importância de tais planos.

\section{Referências}

BULL, Hedley. A sociedade anárquica. Brasília, DF: Imprensa Oficial do Estado; Editora UNB; Instituto de pesquisa de relações internacionais, 2002.

CARMO, Marcia. À revelia do Paraguai, Mercosul anuncia

adesão da Venezuela ao bloco. BBC Brasil. Buenos Aires. 29

junho 2012. Disponível em: <http://www.bbc.co.uk/portuguese/

noticias/2012/06/120629_cupula_mercosul_mc.shtml>. Acesso: 29 mar.

2014.

CORTE paraguaya rechazó reclamo de Fernando Lugo por destitución:

El tribunal superior paraguayo sentenció que "el juicio político es un procedimiento contemplado en la Constitución”. El Comercio. 20 set. 2012 Disponívelem: <http://elcomercio.pe/mundo/actualidad/corteparaguaya-rechazo-reclamo-fernando-lugo-destitucion-noticia-1472418>. Acesso: 29 mar. 2014.

DORATIOTO, Francisco. Maldita guerra. São Paulo: Cia das Letras, 2002. 
GARCIA, Marcos Aurélio. Paraguai, Brasil e o Mercosul. Revista Política Externa, on-line, v. 21, n. 3, jan.-fev.-mar. 2013.

FARIELLO, Danilo; FIGUEIREDO, Janaína; KRAKOVICS, Fernanda. Paraguai será afastado do Mercosul e da Unasul até eleições presidenciais em 2013: Fernando Lugo diz ter sofrido golpe parlamentar e anuncia ida à cúpula do Mercosul na Argentina. O Globo. 24 jun. 2012. Disponível em: <http:/oglobo.globo.com/mundo/paraguai-sera-afastado-domercosul-da-unasul-ate-eleicoes-presidenciais-em-2013-5301933>. Acesso: 29 mar. 2014.

FLECK, Isabel. Brasil mantém no limbo missão no Paraguai. Folha de São Paulo. São Paulo, 27 mar. 2013. Disponível em: <http://www1. folha.uol.com.br/mundo/1253080-brasil-mantem-no-limbo-missao-noparaguai.shtml>. Acesso: 29 mar. 2014.

KANT, Immanuel. A paz perpétua e outros opúsculos. Lisboa: Edições 70 Ltda., 2004.

LAFER, Celso. Descaminhos do Mercosul - a suspensão da participação do Paraguai e a incorporação da Venezuela: uma avaliação crítica da posição brasileira. Revista Política Externa, on-line, v. 21, n. 3, jan.fev.-mar. 2013.

LUGO out in the cold:Why did Paraguay's Congress mount a constitutional putsch against the president? And what happens now? The Economist. 30 jun. 2012. Disponível em: <http://www.economist.com/ node/21557802>. Acesso: 29 mar. 2014.

MATA DIZ, Jamile Bergamaschine. Mercosur: origén, fundamentos, normas y perspectivas.Curitiba: Juruá, 2007.

MAGALHÃES, José Carlos de. Os laudos arbitrais proferidos com base no Protocolo de Brasília para a Solução de Controvérsias. In: Câmara dos Deputados; Comissão Parlamentar Conjunta do MERCOSUL. Solução de controvérsias no Mercosul. Brasília, DF: Câmara dos deputados Coordenação de publicações, 2003.

MERCOSUL. Decisão CMC n. 23/04. [2004a]. Disponível em: <ivospara-solucao-de-controversias-no-mercosul/>. Acesso em: 29 mar. 2014. 
. Protocolo de adesão da República Bolivariana da Venezuela ao Mercosul. [2004b]. Disponível em: <http://www.mercosur.int/msweb/ SM/Noticias/pt/Top_Venezuela_pt.html>. Acesso em: 29 mar. 2014.

. Protocolo de Brasília. [2014a]. Disponível em: $<$ http://www. planalto.gov.br/ccivil_03/decreto/1990-1994/D0922.htm>.Acesso em: 29 mar. 2014.

. Protocolo de Ouro Preto. [2014b]. Disponível em: $<$ http:// www.planalto.gov.br/ccivil_03/decreto/D1901.htm>. Acesso em: 29 mar. 2014.

. Protocolo de Olivos. [2014c]. Disponível em: $<$ http://www. planalto.gov.br/ccivil_03/_ato2004-2006/2004/decreto/d4982.htm>. Acesso em: 29 mar. 2014.

. Protocolo de Ushuaia. [2014d]. Disponível em: $<$ http://www. planalto.gov.br/ccivil_03/decreto/2002/D4210.htm>. Acesso em: 29 mar. 2014.

. Tratado de Assunção. [2014e]. Disponível em: <http://www. planalto.gov.br/ccivil_03/decreto/D1901.htm>. Acesso em: 29 mar. 2014. PAZ, Domingos. Ruptura democrática do e no Mercosul: a "suspensão" do Paraguai e "adesão" da Venezuel. Revista Política Externa, on-line, v. 21, n. 3, jan.-fev.-mar. 2013.

PIMENTEL,Luiz Otávio. Mercado comum do sul. In: BARRAL, Welber (Org.). Tribunais internacionais. Florianópolis: Fundação Boiteux, 2004.

SANTOS, Ricardo Soares Stersi dos. Mercosul e arbitragem internacional comercial. Belo Horizonte: Del Rey, 1998.

. O Mercosul e o sistema de solução de controvérsias estabelecido pelo protocolo de Olivos. In: BACELLAR FILHO, Romeu Felipe; FRIEDRICH, Tatyana Scheila. Aspectos jurídicos da aproximação dos países com vistas ao desenvolvimento. Curitiba: Íthala, 2010.

. As formas pacíficas de resolução de conflitos nas relações internacionais. In: BARRAL,Welber; PIMENTEL, Luiz Otávio; 
CORREA,Carlos M. Direito, desenvolvimento e sistema multilateral do comércio. Florianópolis: Fundação Boiteux, 2008.

SERRANO, Pedro Estevam. Impeachment de Fernando Lugo foi, sim, um golpe: o Brasil precisa renovar a coragem democrática demonstrada no episódio do golpe contra Zelaya em Honduras e apoiar abertamente Fernando Lugo. Carta Capital. 22 jun. 2012. Disponível em: $<$ http:// www.cartacapital.com.br/internacional/impeachment-de-fernando-lugofoi-sim-um-golpe/>. Acesso em: 29 mar. de 2014.

VENTURA, Deisy de Freitas Lima. A ordem jurídica do Mercosul. Porto Alegre: Livraria do Advogado Editora, 1996.

VIANA, Natália. Golpe de Estado contra Fernando Lugo começou a ser tramado em 2008. Ópera Mundi. 4 de fevereiro de 2013. Disponível em: <http://operamundi.uol.com.br/conteudo/reportagens/26979/ golpe + de + estado + contra + fernando + lugo + comecou $+a+$ ser + tramado + em + 2008.shtml>. Acesso em: 29 mar. 2014.

Ricardo Soares Stersi dos Santos é professor dos Programas de PósGraduação em Direito e em Relações Internacionais da Universidade Federal de Santa Catarina.

E-mail: rstersi@hotmail.com

Endereço profissional: Universidade Federal de Santa Catarina, Reitoria, Centro de Ciências Jurídicas. Sala 329 - Trindade. CEP:88040900 - Florianópolis, SC Brasil - Caixa-postal: 476.

Rafael de Miranda Santos é Mestre e Doutorando em Direito pelo Programa de Pós-Graduação em Direito da Universidade Federal de Santa Catarina.

E-mail: r.m.santos@posgrad.ufsc.br

Endereço profissional: Universidade Federal de Santa Catarina, Centro de Ciências Jurídicas. Sala 329 - Trindade. CEP: 88040900 - Florianópolis, SC Brasil - Caixa-postal: 476. 
